\title{
Erratum to: ERCP via gastrostomy vs. double balloon enteroscopy in patients with prior bariatric Roux-en-Y gastric bypass surgery
}

Eun Kwang Choi - Michael V. Chiorean - Gregory A. Coté • Ihab I. El Hajj • Darren Ballard • Evan L. Fogel • James L. Watkins • Lee McHenry •

Stuart Sherman · Glen A. Lehman

Published online: 29 August 2013

(C) Springer Science+Business Media New York 2013

Erratum to: Surg Endosc (2013) 27:2894-2899

DOI 10.1007/s00464-013-2850-6

The name of the fourth author is misspelled. Ihab I. El Hajj is the correct spelling with El Hajj being the family name.

The online version of the original article can be found under doi:10.1007/s00464-013-2850-6.

E. K. Choi · M. V. Chiorean - G. A. Coté .

I. I. El Hajj · D. Ballard - E. L. Fogel · J. L. Watkins .

L. McHenry $\cdot$ S. Sherman · G. A. Lehman $(\bowtie)$

Division of Gastroenterology/Hepatology, Department of

Medicine, Indiana University Medical Center, 550 N. University

Boulevard, UH 4100, Indianapolis, IN 46202, USA

e-mail: glehman@iupui.edu 